\title{
Cadeias produtivas sustentáveis no desenvolvimento territorial: a castanha na Bolívia e no Acre, Brasil
}

\author{
Sustainable production chains in territorial development: the brazil-nut in Bolivia \\ and Acre, Brazil
}

\section{Les chaines de production durable dans le développment territorial: noix du brésil en Bolivie et Acre, Brésil}
Cadenas sostenibles de producción en el desarrollo territorial: la almendra en Bolivia y Acre, Brasil

\author{
Markus Erwin Brose* \\ (mbrose@uol.com.br)
}

Recebido em 28/11/2014, revisado e aprovado em 17/06/2015; aceito em 12/11/2015

DOI: http://dx.doi.org/10.20435/1518-70122016108

\begin{abstract}
Resumo: A cadeia produtiva da castanha tem sua produção limitada a dois territórios vizinhos, historicamente baseada na servidão por dívida. Ambas as regiões passaram por profundas modificações nas últimas décadas e oferecem rara oportunidade para comparar as condições de trabalho em uma mesma cadeia produtiva. Apresentamos indicadores de que, ao contrário da Bolívia, a mobilização social no Acre viabilizou a reestruturação da cadeia produtiva, tornando-a mais inclusiva e sustentável.

Palavras-chave: Servidão por dívida. Castanha. Amazônia.

Abstract: The Brazil-nut production chain is limited to two neighboring territories, historically based on debt bondage. Both regions have undergone profound changes in recent decades and offer a rare opportunity to compare the working conditions in the same supply chain. We present indicators that, unlike Bolivia, social mobilization in Acre allowed the restructuring of the supply chain, making it more inclusive and sustainable. Key words: Debt bondage. Brazil-nut. Amazon.

Résumé : La chaîne de production des noix du Brésil a limité les deux territoires voisins, historiquement basée sur la production de la servitude pour dettes. Les deux régions ont subi de profonds changements au cours des dernières décennies et offre une rare occasion de comparer les conditions de travail dans la même chaîne de production. Indicateurs présents que, contrairement à la Bolivie, la mobilisation sociale à Acre a permis la restructuration de la chaîne de production, la rendre plus inclusive et durable.

Mots-clés: Servitude pour dettes. Noix du Brésil. Amazon.

Resumen: La cadena de producción de almendra es limitada a dos territorios vecinos, históricamente basado en la producción de la servidumbre por deudas. Ambas regiones han experimentado profundos cambios en las últimas décadas y ofrecen una rara oportunidad de comparar las condiciones de trabajo en la misma cadena de suministro. Presentamos indicadores que, a diferencia de Bolivia, la movilización social en Acre permitió la reestructuración de la cadena, por lo que es más inclusiva y sostenible.
\end{abstract}

Palabras clave: Servidumbre por deudas. Almendra. Amazonia.

\section{INTRODUÇÃO}

A partir de uma análise crítica dos estudos sobre desenvolvimento rural, Abramovay (2006) propõe a superação dos enfoques normativos em voga, especialmente o conceito de Capital Social, e recomenda: "o estudo empírico dos atores e de suas organizações", incluindo, também, os mecanismos de governança:

Encarar os territórios como campos em que se defrontam protagonistas com interesses diversos, estudar os processos localizados de cooperação, não como expressão idílica de virtude cívica e sim como forma de dominação [...]. (ABRAMOVAY, 2006, p. 67).

As ciências sociais dispõem de ampla bibliografia que analisa a origem de lideranças engajadas em períodos recentes, seja em sindicatos (CONCEIÇÃO, 1980), movimentos sociais urbanos (CABANES, 2002), seja em movimentos rurais (ROTHMAN, 1996; SCOLESE, 2008), que moldaram novas formas de governança territorial.

A formação dessas lideranças deu-se no enfrentamento da exclusão social, o que permite constatar que esse padrão de formação de lideranças não segue o modelo dos Estados

* Universidade de Santa Cruz do Sul (UNISC), Santa Cruz do Sul, RS, Brasil. 
Unidos da América, aplicado por Putnam (1995) à Itália, onde a motivação dos jovens inicia pela vivência da harmonia social em grupos de colecionadores de selo, escoteiros ou entidades caritativas. $O$ padrão de formação de lideranças comunitárias que inovam na governança territorial no Brasil é mais similar à experiência da região da Terza Italia, interpretada por Trigilia (1989) pelo embate entre as subculturas políticas católica e comunista, ou na região de Kerala, na Índia, interpretada por Sen (1990) pelo embate dos partidos de orientação marxista contra a pobreza. Nesse sentido, a harmonia social proposta pela concepção do Capital Social parece pouco adequada para a análise da governança em territórios rurais no Brasil.

A abordagem dos mercados proposta por Abramovay (2004), originária da Nova Sociologia Econômica (NSE), baseia-se na concepção de que os mercados não correspondem aos mecanismos abstratos de equilíbrio descritos em manuais econômicos, afirmando que os mercados são estabilizados mediante coalizões políticas que estabelecem hierarquia entre os atores. O autor constata vínculo entre território e mercados, visto que os atores dependem do beneficiamento dos recursos naturais.

Abramovay et al. (2010) detalham essa concepção para a Amazônia, território onde identificaram duas estratégias para incorporação de movimentos sociais e ambientais às cadeias produtivas:

- o enfoque funcional, preocupado com a reputação do produto que leva empresas a adotar certificação e rastreabilidade (p.ex., madeira), e

- as mesas redondas, espaço no qual os principais agentes da cadeia produtiva definem novas práticas mediante o diálogo (p.ex., soja e carne).

Costa; Piketty; Abramovay (2013) detalham o caso do Proambiente, concebido pelo movimento sindical, que acabou não se tornando política pública. Os autores enfatizam que esse projeto poderia ter fortalecido o manejo de Produtos Florestais Não-Madeireiros (PFNM) como fonte de renda para seringueiros e assentados na Amazônia.

Para as cadeias produtivas de PFNM, torna-se também relevante considerar que estas têm origem nas práticas de etnobiologia
(RIBEIRO, 1986; RIBEIRO, 2011). Esses conhecimentos foram assimilados pelos migrantes nordestinos ao tornarem-se seringueiros e ribeirinhos na Amazônia, adaptando práticas ancestrais no acesso desses produtos ao mercado (LACERDA, 2010). Nesse sentido, as cadeias produtivas de PNFM representam construções sociais em tensão permanente, que podem ser ambientalmente sustentáveis. Porém não ocorre sustentabilidade se não houver eliminação da pobreza na cadeia produtiva. As alternativas de baixo investimento de capital disponíveis às famílias extrativistas: I) sobre-exploração dos PFNM, ou II) a pecuária de pequena escala, põem em risco a sustentabilidade ambiental (MACIEL; REYDON, 2008).

Incremento da renda obtida com PFNM constitui um dos pilares da Política Estadual de Valorização do Ativo Ambiental Florestal do Acre, tornada lei em 2008, além de fomentar renda em áreas já desmatadas, combinando as duas estratégias para manter a floresta em pé. A presente pesquisa visa contribuir para esse debate, analisando o histórico de inclusão social pelos PFNM no Acre para o caso da castanha.

Quanto à cadeia produtiva da castanha, foi realizado levantamento de campo entre setembro de 2011 e setembro de 2014, em diversos pontos do Vale do Rio Acre, bem como em núcleos urbanos do norte da Bolívia: Guayaramerín, Cachuela Esperanza, Riberalta, Vila Evo Morales e Cobija. A coleta de dados foi realizada através de visita a comunidades produtoras, empresas, cooperativas e órgãos públicos. Foram conduzidas 27 entrevistas semiabertas com produtores, assessores, lideranças comunitárias e pesquisadores. Foi realizada revisão bibliográfica na Biblioteca Pública do Acre e nas bibliotecas da Universidade Federal de Rondônia e do Acre.

Este artigo está organizado em três seções adicionais. Na próxima seção, revisamos a hipótese de que não existe contradição entre modernas cadeias produtivas e condições de trabalho análogas à escravidão. Na seção seguinte, os dados coletados são agrupados em três partes, contendo breve descrição da cadeia produtiva da castanha e suas ramificações na Bolívia e no Acre. Na terceira e última seção, apresentamos as considerações finais. 


\section{CONTRADIÇÕES DO MERCADO DE TRABALHO}

Historicamente, o sistema capitalista de produção e comércio dependeu em certa escala do trabalho forçado, seja diretamente nos países centrais, ou terceirizado em países periféricos. Brass e Van Der Linden (1997) buscam demonstrar a coexistência, ou mesmo compatibilidade, dos sistemas de trabalho livre e forçado ao longo da história. Contrário à percepção geral de que na globalização haveria um tipo de desenvolvimento linear rumo ao ideal do trabalhador livre, que negocia sua mão de obra de igual para igual com o empregador, os autores argumentam que formas de escravidão moderna não desapareceram durante o Século 21. Empresas, e mesmo cadeias de produção, competitivas no capitalismo maduro e inseridas no mercado internacional, estão baseadas em diferentes formas de trabalho forçado. Conforme realça Brass (2011), formas coercitivas de trabalho não constituem mero fenômeno transitório, que possibilitaria uma acumulação primitiva a ser superada em etapas tardias, mas constituem parte integrante do sistema econômico global.

O primeiro passo para a existência do trabalhador livre ocorre quando o posseiro, o pescador ou o indígena, perde sua terra. No sentido clássico da teoria marxista, ao não dispor mais do ativo terra, o camponês passa a pertencer à classe proletária como peão, trabalhador rural ou migrante, passando a buscar trabalho remunerado. Brass (1999) argumenta que, em muitos casos, a passagem linear para proletário livre é impedida por dívidas, que mantêm o trabalhador preso a um patrão. De acordo com o autor, a servidão por dívida origina o que classifica como desproletarização, conhecido na Amazônia como aviamento ou sistema de barracão, no qual o trabalhador não está livre, não está verdadeiramente proletarizado para negociar sua força de trabalho.

Ainda segundo Brass (1999), estudar a servidão por dívida possui relevância para entendermos a luta de classes em territórios rurais. Os proprietários dos ativos produtivos mantém o trabalhador rural preso à propriedade através do endividamento, não apenas achatando o custo da mão de obra, mas, em especial, individualizando a relação de trabalho. Desta forma, prevenindo o surgimento de um sentimento de pertencimento, de grupo e de classe (HAGAN; WELLS, 2000).

No território onde o trabalhador é livre para atuar coletivamente, após a fixação dos migrantes, vão sendo estabelecidos vínculos interpessoais de confiança e ação conjunta. Criam-se organizações mais simples, como associações, passando por sindicatos, até as mais complexas, como cooperativas de crédito. Kohn (2003), seguida por Solt (2004), argumenta que essas organizações coletivas é que lutam pela expansão da cidadania e dos direitos do trabalhador, que favorecem a boa governança territorial.

\section{EXPORTANDO CASTANHA-DO- BRASIL}

Somente através do extrativismo, é possível produzir a castanha descascada aceita no mercado internacional. A polinização das flores da castanheira depende de insetos nativos, inviabilizando o cultivo comercial em larga escala em outros países, como foi o caso do cacau ou da seringueira. O potencial de renda pelo manejo dos castanhais nativos é de tal ordem que deu origem a cidades como Santarém e Puerto Maldonado, bem como a diversas reservas extrativistas (FILOCREÃO, 2008). Na Amazônia peruana, os castanhais são propriedade do Estado e objeto de concessão (PEÑA, 2010).

A castanha é o único integrante do comércio internacional do setor de amêndoas e nozes não produzido por cultivo, dependendo do extrativismo, cuja produtividade varia ao longo dos anos, favorecendo flutuação de preços e especulação nos mercados. O que origina, de um lado, acentuado nível de pobreza entre as famílias extrativistas e, por outro lado, um significativo grau de especialização e concentração por parte dos intermediários. Assim, no Brasil, estabeleceu-se historicamente um monopólio, sendo uma única família na cidade de Belém proprietária das três principais plantas processadoras, com efeitos sociais perversos (SAKAMOTO, 2004; MARTINS, 2004).

Ao longo do Século 19, o Brasil tornou-se o principal exportador global de castanha, produto com tradição nas vendas em feriados 
como Natal e Ação de Graças (EUA e Reino Unido), em um nicho de alto valor agregado no processamento em chocolate e doces (Holanda, Alemanha e Itália). Estima-se que atualmente a castanha representa mercados da ordem de USD 150 milhões/ano, que pareciam garantidos:

As indústrias boliviana e peruana não têm sido capazes de manter seus compromissos, tanto na qualidade, como na entrega do produto. Normalmente, um embarque da Bolívia pode chegar atrasado à costa leste dos EUA, incompleto, ou simplesmente não chegar. Quando chega, também é comum as castanhas não serem do tipo das contratadas, estão danificadas ou estragadas. $\mathrm{O}$ empresário brasileiro, portanto, não está sujeito à concorrência de nossos vizinhos. (SEBRAE-AC, 1995, p. 36).

Porém, a partir de 1998, a Bolívia chegou ao ranking de primeiro produtor mundial, ocupando $60 \%$ do mercado, passando da exportação de 15.000 t/ano para o atual patamar de $60.000 \mathrm{t} / \mathrm{ano}$. Qual a origem desta reviravolta na cadeia produtiva?

Nos anos 1990, por motivo da política de proteção ao consumidor, a União Europeia estabeleceu normas para qualidade na castanha, reduzindo a tolerância dos índices de contaminação por aflatoxinas. Isso exigiu tanto rastreabilidade, como análise por laboratório certificado, para cada lote de castanha descascada. Pela baixa flexibilidade dos poucos operadores da exportação brasileira, perda de castanhais pelo desmatamento no Pará, bem como ausência de uma política específica, as empresas em Belém concentraram-se em atender ao mercado interno com castanha em casca.

\subsection{Resposta do setor produtivo na Bolívia}

Na Bolívia, houve ação preventiva às mudanças. $\mathrm{O}$ arranjo produtivo local da castanha é coordenado por um grupo de 24 beneficiadoras de diferente tamanho, integrado a transportadoras e empresas financeiras, estando concentrado na cidade de Riberalta, na divisa entre os departamentos de Pando e Beni (STOIAN, 2000). Dali a castanha embalada segue, por via terrestre, até a capital La Paz, de onde é exportada pelos portos do Chile.
Exportando 99\% de sua produção, metade para a Europa, o arranjo produtivo de Riberalta acompanhou as mudanças do mercado global com apoio dos seus principais compradores. Em 1991 o governo da Holanda e o Banco Mundial financiavam a criação da Fundación Bolivia Exporta, que identificou a castanha como uma das cadeias produtivas estratégicas para o país. Mediante linhas de financiamento subsidiado e assistência técnica, em meados dos anos 1990 a Câmara de Comércio Exterior estabeleceu dois centros tecnológicos para promover boas práticas, um na cidade de Riberalta com laboratório de controle de qualidade e sanidade, e outro na cidade de Cobija para capacitação. Esse processo foi acompanhado por cooperação científica do governo da Holanda, através do Programa Manejo de Bosques de la Amazonia Boliviana (PROMAB) da Universidade de Utrecht.

Paralelamente, houve parceria no Proyecto para Cooperación Técnica para el Desarrollo y Promoción de Exportaciones, coordenado pelo International Trade Center (ITC), organização da ONU para fomento de exportação de pequenas empresas. Com recursos do governo da Suíça, foi realizada qualificação técnica das empresas de Riberalta em áreas como embalagem, contatos com agentes do mercado e análise de pontos críticos (RIENSTRA, 2004). As empresas investiram em equipamentos, e o arranjo produtivo local deu um salto de produtividade dobrando a produção em cinco anos, gerando cerca de $20 \%$ do volume de exportações do país (HELBINGEN, 2001).

No debate internacional, esse feito é celebrado. Rienstra (2004) ressalta o potencial de redução da pobreza no norte da Bolívia. Stoian (2005) classifica o trabalho na castanha como o "melhor de dois mundos", pois o castanheiro pode morar na área urbana e trabalhar no meio rural e, não sendo um trabalho fixo, permite à família a flexibilidade para decidir se quer ou não um aviamento naquela safra. Segundo Coslovsky (2014), esse sucesso foi obtido porque os exportadores bolivianos são mais capazes e eficientes que os brasileiros.

Mas, qual o critério de sucesso? Coslovsky (2014, p. 32) classifica-os como "produtores bolivianos". A bibliografia converge no sentido de registrar 24 empresas em Riberalta. O termo técnico para classificar esses atores é 
processadores. Um elo importante da cadeia produtiva, popularmente conhecidos como atravessadores:

Um aspecto problemático desse mercado é a persistente figura do 'atravessador' no processo de comercialização da castanha-do-brasil, contribuindo para a redução da renda do extrativista [...] esses atores sociais aproveitam-se da situação de isolamento dos castanheiros nas florestas e determinam um preço [...] também fazem o 'aviamento' dos gêneros alimentícios [...] criando assim uma relação de exploração e dependência. (SILVA, 2010, p. 115).

Produtores da castanha, no sentido restrito do termo, ou fornecedores da matéria prima, são os castanheiros, conhecidos na Bolívia como zafreros, o equivalente a boia-fria, cujo número é estimado em 15.000 famílias, cerca de $70 \%$ da população da região norte da Bolívia. Importa ressaltar que quem alcançou sucesso econômico com a castanha na Bolívia pós-1998 foram os 24 processadores. Os cerca de 15.000 zafreros, fornecedores de matéria-prima, não experimentaram semelhante desenvolvimento econômico. A população dessa região da Bolívia apresenta os maiores índices de pobreza do país, submetendo-se ao sistema de dívida, o habilito, para a safra. Os analistas do Índice de Desenvolvimento Humano (IDH) na Bolívia resumem:

\begin{abstract}
El norte amazónico vive um retraso em aspectos sociales y un aceleramento em lo económico [...] históricamente hubo una débil presencia del Estado [...] la economia amazónica gira alrededor de un solo produto, la castaña [...] se debe buscar modernizar las relaciones laborales en el marco de leyes estables. Las nuevas industrias deben albergarse em las leyes del trabajo, en una logica moderna de relación obrero-patronal. (CUELLAR, 2003, p. 21).
\end{abstract}

Anualmente os zafreros são contratados informalmente no sistema de dívida do habilito para embrenharem-se na floresta na estação da chuva, correndo contra o tempo para que a castanha não absorva demasiada umidade, enfrentando insalubridade por própria conta e risco. Paralelamente, cerca de 5.000 mulheres, desempregadas durante o resto do ano, trabalham na safra como quebradeiras nas indústrias em Riberalta, sem contrato fixo de trabalho, remuneradas por produção (MONTERO; POVEDA, 2003).

Análise por Mori (1992) para o início da década 1990 estima a renda bruta aos extrativistas em USD 97/ hectare, na estimativa para a empresa exportadora uma remuneração equivalente a USD 176/hectare, enquanto o preço da castanha, em um supermercado da Flórida, renderia USD 1.060/hectare. Duas décadas mais tarde, estudo por Keane; Lemma (2009) indicou que 52\% do valor agregado pela cadeia produtiva permanece com as empresas de processamento, restando $13 \%$ para as 15.000 famílias de castanheiros e outros $15 \%$ para as 5.000 quebradeiras.

A servidão por dívida que marca a região não é clandestina, sendo registrada de forma recorrente pela mídia (CRESPO, 2005), por organizações internacionais (GARLAND; SILVA-SANTISTEBAn, 2005; TORRES, 2010) e pela produção acadêmica (HELBINGEN, 2001; ASSIES, 2002; PACHECO et al., 2008). Estudo de campo pela ONG Verité (2011) confirmou recentemente o uso de trabalho infantil e a servidão por dívida na produção da castanha.

Em 2007, a nova Constituição da Bolívia proibiu o trabalho forçado e o trabalho infantil. Com apoio do Fundo das Nações Unidas para a Infância (UNICEF) e Organização Internacional do Trabalho (OIT) foi criado o Conselho Nacional de Erradicação do Trabalho Infantil, com uma subcomissão para tratar da cadeia produtiva da castanha (UNICEF, 2008; LOBO, 2009). Em 2010, o Ministério do Trabalho da Bolívia iniciou, com recursos do governo da Suíça, projeto para erradicar a servidão por dívida nas safras da cana-de-açúcar e da castanha.

Esse contexto levou o governo da Bolívia a intervir na cadeia produtiva, criando, em 2009, a empresa pública Empresa Boliviana de Almendra (EBA), para viabilizar remuneração mais justa aos castanheiros. A EBA instalou, em 2011, uma planta processadora na vila El Sena (OEMER, 2004). Em 2013, a empresa obteve registro comercial no porto de Hamburgo, Alemanha, em sociedade com importadora local. 


\subsection{Impactos e reação no Acre}

Os cerca de 5.000 seringueiros/castanheiros que produziam $18.000 \mathrm{t} /$ ano no estado do Acre - o segundo maior produtor do país - viram sua renda familiar ameaçada pelo avanço da exportação boliviana baseada no baixo preço da mão de obra. A produção caiu na década de 1990, chegando, em 1997, ao patamar mínimo de 3.000 t/ano. Com a redução tanto do volume produzido, como do preço praticado nas praças de Manaus e Belém, a cadeia produtiva no Acre viu-se ameaçada em sua existência. A virada deu-se em 1999, passando ao atual patamar de produção de 14.000 t/ano (MACIEL, 2007). Qual a origem dessa retomada da produção acreana?

A reação teve início pelo movimento social dos seringueiros que, em aliança com os Sindicatos de Trabalhadores Rurais do vale do rio Acre, combateram o aviamento:

\begin{abstract}
O seringueiro com aviamento, além de não poder produzir alimentos, era monopolizado totalmente, quer quanto ao produto de seu trabalho, quer quanto às formas de prover sua subsistência. Uma forma para assegurar essa dedicação exclusiva à extração do látex era garantir seu isolamento, de modo que nada o dispersasse dessa tarefa mecânica. Nem a convivência familiar era permitida. (RANZI, 2008, p. 179).
\end{abstract}

O êxito das lutas populares permitiu que as famílias extrativistas que viviam nos seringais não fossem mais vinculadas ao seringalista, com direito de colocar a castanha livremente no mercado. E, com a ampliação dos direitos civis e econômicos pela Constituição de 1988, o sistema de exploração dos seringueiros pelos proprietários das terras chegou ao fim nos anos 1990.

Tal como ocorreu no mesmo período em outra cadeia produtiva baseada na escravidão, o cacau no sul da Bahia (AGUIAR FILHO, 1976), os extrativistas, coletivamente denominados Povos da Floresta, tornaram-se os protagonistas quanto ao futuro da cadeia produtiva da castanha no Acre.

Mas o principal limitante do acesso dos seringueiros ao mercado reside em sua descapitalização, que implica o fato de que, apesar de terem acesso privilegiado aos recursos da floresta, as famílias necessitam receber pagamento à vista no ato de entrega do produto (látex, castanha, açaí, óleo de copaíba etc.). Isso pressiona o capital de giro da empresa compradora - seja intermediário, processador ou cooperativa - e exige elevada capacidade gerencial para não inviabilizar a empresa.

O primeiro teste para promover o acesso de forma coletiva ao mercado foi a criação de diversas cooperativas e associações comunitárias dos seringueiros nos vales dos rios Acre e Juruá, em início dos anos 1980. Por ausência de capital de giro e baixa capacidade gerencial, não lograram estabelecer um novo padrão de comercialização. Em 1987, o movimento dos seringueiros realizou ampla mobilização entre as centenas de famílias extrativistas no alto vale do rio Acre, do que resultou já em 1988 a criação da Cooperativa Agroextrativista de Xapuri (CAEX) (RODRIGUES, 2009).

Em 1990, o movimento dos seringueiros lograva uma das suas maiores vitórias mediante a criação da Reserva Extrativista Chico Mendes, cobrindo um milhão de hectares de floresta em Xapuri e municípios vizinhos. Esse modelo de proteção à floresta em pé representou uma mudança das políticas agrárias do Governo Federal a favor do uso coletivo da terra. Com apoio de organizações não governamentais (ONGs) e financiamento público, foi construída, no mesmo ano, uma usina de beneficiamento na cidade de Xapuri, pondo fim ao monopólio de processamento no porto de Belém.

A CAEX tornou-se a empresa âncora dos esforços dos movimentos sociais em tornar a cadeia produtiva da castanha mais inclusiva. Porém as oscilações na quantidade e qualidade da produção da castanha, os preços menores da castanha na Bolívia, as limitações de capital de giro e capacidade gerencial, bem como os altos juros no país, levaram ao endividamento e à paralisação da usina em 1992 (MACIEL, 2007).

Paralelamente, em 1993, foi fundada a Cooperativa Mista de Produção Agropecuária e Extrativismo de Brasiléia e Epitaciolândia (CAPEB), que inaugurou, em 1999, uma usina de beneficiamento de castanha. Parte da produção era comercializada para a empresa boliviana Tahuamanu SA, na vizinha cidade 
de Cobija, que ofereceu apoio permitindo à CAPEB acessar financiamento para comprar as primeiras juntas de boi distribuídas às famílias das localidades mais remotas (SILVA, 2010).

Os movimentos sociais do Acre continuaram, em outras frentes, a luta por melhores condições de vida e, em novembro de 1998, sua plataforma política venceu as eleições para governador. Em janeiro de 1999, assumia o Executivo estadual uma equipe de técnicos e militantes que instituiu o Governo da Floresta. Entre as primeiras medidas, figura a criação da Secretaria de Floresta e Extrativismo e uma linha de subsídio à produção do látex, o que incentivou o retorno aos seringais de seringueiros que haviam migrado para cidades, assim ampliando também a coleta e comercialização da castanha. Para a castanha foi estabelecida uma política de preço mínimo, que operou entre 1999 e 2002 mediante compra antecipada da produção (MACIEL, 2007).

Foi criado o Instituto de Terras do Acre, que deu início à regularização fundiária e titulação das terras ocupadas e manejadas pelas famílias extrativistas através de diversas modalidades de projetos de assentamento. $\mathrm{O}$ seringueiro, de trabalhador rural em regime análogo à escravidão, passou a ser proprietário da terra e das castanheiras. Nos anos 1990, um conjunto de ONGs iniciou o trabalho de erradicação do analfabetismo, culminando com a universalização do acesso ao ensino público para crianças e adolescentes da região, contribuindo para erradicar o trabalho infantil.

Em 2001, os movimento sociais articularam a criação da Cooperativa Central de Comercialização Extrativista do Acre (Cooperacre), tornando-se nova âncora da cadeia produtiva da castanha. Dirigida por lideranças comunitárias, essa organização de segundo nível congrega 25 associações e cooperativas individuais de 10 municípios do estado, atendendo a 1.800 famílias extrativistas filiadas e mantendo cerca de 150 empregos diretos. Com orientação técnica pela Embrapa foi iniciado processo de capacitação nas comunidades para adoção de boas práticas de manejo da castanha. A Cooperacre conseguiu atingir nível zero de aflatoxina, monitorado através de análises periódicas realizadas em laboratório da Universidade de São Paulo (USP).

A partir de 2005 foi acessado o Programa de Aquisição de Alimentos (PAA), executado pela Companhia Nacional de Abastecimento (Conab), para possibilitar uma política de preços mínimos da castanha. $O$ preço pago no Acre, que estava em $\mathrm{R} \$ 4,00 /$ lata de $10 \mathrm{~kg}$ em 1997, subiu para o patamar de $\mathrm{R} \$ 18,00$ / lata em 2005. Em média, os preços praticados pelas cooperativas no período 1999 e 2006 estiveram 45\% acima do mercado livre (MACIEL, 2007). A partir de 2003, com maior concorrência, o preço praticado pelo mercado ficou acima do patamar do preço mínimo da Conab.

Em 2003, a União Europeia vetou qualquer importação de castanha embarcada do Brasil. Entre 2006 e 2009, o Ministério da Agricultura e Pecuária e a Embrapa receberam cooperação técnica por consórcio integrado pelo Centro de Pesquisa CIRAD/França, National Food Administration/Suécia e Central Science Laboratory/Reino Unido, no valor de um milhão dólares financiado pela World Trade Organization (WTO), buscando estabelecer práticas para redução da aflatoxina em castanhas produzidas no Acre e no Pará. O relatório de avaliação ressalta, porém, que as atividades de pesquisa tiveram pouca integração com as práticas comerciais, falhando em ampliar a exportação brasileira (BENTANCUR, 2010). Assim, a partir de 2003, cresceu a exportação de castanha em casca para as beneficiadoras da Bolívia, tornando-se, em 2005, o segundo item na pauta de exportação do Acre.

Buscando fomentar a agregação de valor no Acre para comercialização da castanha processada, com investimento de $\mathrm{R} \$ 3,6$ milhões compartilhados pela Superintendência da Zona Franca de Manaus e o Governo Estadual, foram modernizadas e ampliadas as usinas nos município de Xapuri e Brasiléia, sendo reinauguradas em 2006. A CAPEB coordenou uma iniciativa regional para superar os gargalos tecnológicos, mobilizando recursos de ONGs, além da assessoria técnica da Embrapa. A área piloto envolvendo 30 famílias no Seringal Porvir, após capacitação dos seringueiros em boas práticas de manejo e mapeamento de cada castanheira com sistema de posicionamento via satélite, recebeu, em 
2004, a certificação Fair Trade e selo orgânico pelo Instituto Biodinâmico (IBD). Em 2005, as primeiras famílias iniciaram exportação para a Itália obtendo preço de $\mathrm{R} \$ 28,00 /$ lata, passando a castanha, de $23 \%$, a contribuir com $50 \%$ da renda das famílias envolvidas (MACIEL, 2007).

Em 2009, foi exportada castanha descascada através de redes de comércio justo para a Alemanha; em 2010, foram 32 t para a Itália. Entre 2010 e 2012, o comércio da castanha descascada concentrou-se no mercado nacional, com crescimento de $350 \%$ em relação ao volume comercializado e de $660 \%$ em relação ao valor faturado. A Cooperacre investiu $\mathrm{R} \$ 2,5$ milhões na renovação e ampliação da usina de beneficiamento no município de Xapuri. Na safra 2012/13, o estado do Acre produziu cerca de $15.000 t$ de castanha em casca, das quais cerca de $5.000 \mathrm{t}$ foram exportadas para a Bolívia. O preço médio no mercado livre oscilou em torno de R\$16,00/ lata (BAYMA, 2012).

Em 2013, a Cooperacre, com receita bruta de R\$ 25 milhões/ano, sendo fornecedora da Nestlé e Nutrimental, comprou cerca de R 15 milhões/ano de seus associados. O Governo do Acre anunciou investimento de $\mathrm{R} \$ 9$ milhões em uma terceira unidade a ser administrada pela Cooperacre, aumentando em $50 \%$ o volume de castanha descascada.

\section{ANÁLISE E CONCLUSÕES}

Plano de desenvolvimento regional para o norte da Bolívia encomendado pelo Banco Mundial em 1993, afirmava que: "independente da sua organização e do modelo de distribuição de benefícios, a cadeia produtiva da castanha será particularmente favorável à conservação ambiental" (ASSIES, 1999, p. 95). Com base nos dados coletados, argumentamos, ao contrário, que o modelo de distribuição de benefícios é central para interpretar os arranjos produtivos locais da castanha. $\mathrm{O}$ caso boliviano parece confirmar a hipótese de Coslovsky (2014) de não haver pré-condicionantes para que uma região fronteiriça e atrasada possa promover o crescimento econômico através do acesso a mercados globalizados. Porém o caso do Acre confirma a hipótese de que crescimento econômico, por si só, não promove desenvolvimento regional ou local. Mercados dinâmicos, via de regra, são excludentes (TOLEDO, 2014).

A coleta e a comercialização da castanha podem ser consideradas essenciais para a manutenção da floresta em pé, a dimensão ambiental da sustentabilidade, como evidenciado pela experiência da Resex Chico Mendes no Acre. Mas a cadeia produtiva da castanha não se sustenta enquanto não garantir a inclusão social, evidenciado pela lenta, mas contínua, expansão da pecuária na Resex Chico Mendes. A erradicação da servidão por dívida representa apenas o primeiro passo rumo à correção de externalidades do mercado e promoção da qualidade de vida para os castanheiros e quebradeiras, conceito cunhado no Acre pelo termo Florestania.

Entre os pré-requisitos para que a cadeia produtiva da castanha no Acre tenha se tornado inclusiva, podemos citar, i) mobilização social para combater a exclusão a partir de uma nascente consciência de classe; ii) acesso continuado a políticas públicas, estatais e não estatais, que possibilitaram inovação e criatividade em empresas sociais; iii) um Estado forte, comprometido com a causa da erradicação da servidão por dívida, distribuindo ativos produtivos, eliminado trabalho forçado e trabalho infantil, erradicando o analfabetismo e garantindo o acesso ao judiciário independente. A pressão social modernizou a cadeia produtiva da castanha segundo critérios de comércio justo, a democratização dos mercados deu-se pelo estabelecimento de uma nova hegemonia.

A União Europeia adota normas restritas para proteger seus consumidores e vem adotando normas ambientais: "De olho no mercado estrangeiro, o setor [da agropecuária] passou a se preocupar mais com os passivos ambientais. O mercado europeu é muito exigente em relação a essas questões" (TOLEDO, 2014, p. 2). O mesmo, porém, não se aplica a condicionantes sociais, como evidencia o caso da castanha da Bolívia. Contrário à percepção corrente na opinião pública, a globalização não tem impedido, muito menos erradicado, a servidão por dívida na cadeia produtiva da castanha. $\mathrm{O}$ esperado efeito modernizador e difusor da cidadania para o trabalho livre pela mão invisível da globalização não se manifestou ao longo dos últimos vinte anos no norte da Bolívia. Na raiz 
do problema parece estar a eterna dívida, que gera a desproletarização conforme tipologia proposta por Brass (1999).

Na comparação entre o sistema produtivo boliviano e acreano, é possível argumentar que, sendo iguais as demais condições produtivas, a servidão por dívida viabiliza o baixo custo da mão de obra na Bolívia, depreciando o valor de venda da castanha. A limitada rentabilidade da castanha, por sua vez, contribui para o fracasso econômico das Reservas Extrativistas no Brasil, cada vez mais dependentes de programas de transferência de renda como Bolsa Família e Bolsa Verde. Esta não é uma constatação isolada para a Amazônia, visto que a redução do custo da mão de obra e a decorrente distorção do mercado são temas recorrentes:

A Confederação Nacional da Indústria levou 180 empresários para o Paraguai. Durante três dias, os brasileiros ouviram um mantra: venham, tragam seu mercado e usem o baixo custo paraguaio para enfrentar a China. [...] Além dos custos menores, um movimento sindical urbano ainda pouco atuante, uma mão de obra jovem e fácil de ser treinada, pouquíssimas reclamações trabalhistas e um governo 'empresarial' se somam à lista de atrativos. (NEUMANN, 2014, p. 4).

Preços, mercados, condicionantes sociais e jurídicas da cadeia produtiva da castanha são construções sociais. Não pelo mercado, mas pela sociedade de cada território. Esta parece ser a diferença entre o caráter inclusivo ou excludente da castanha.

\section{REFERÊNCIAS}

ABRAMOVAY, Ricardo. Entre Deus e o diabo: mercados e interação humana nas ciências sociais. Tempo Social. São Paulo. v. 16, n. 2, p. 35-64, 2004.

Para uma teoria dos estudos territoriais. In: MANZANAL, M.; NEIMAN, G.; LATTUADA, M. (Ed.) Desarrollo rural: organizaciones, instituciones y territorios. Buenos Aires: Ediciones Ciccus, 2006.

ABRAMOVAY, Ricardo; VOIVODIC, A.; CARDOSO, F.; CONROY, M. Social movements and NGOs in the construction of new markets. Economic Sociology, Strassburg. v. 11, n. 2, p. 24-30, 2010.

AGUIAR FILHO, Adonias. Sul da Bahia: chão do cacau, uma civilização regional. Rio de Janeiro: Civilização Brasileira, 1976.
ASSIES, Willem. Amazon nuts, forests and sustainability in Bolivia and Brazil. Em: ROS-TONEN, M. (Ed.) NTFP research in the Tropenbos Programme: results and perspectives. Wageningen: Tropenbos Foundation, 1999.

From rubber estate to simple commodity production: agrarian struggles in the Northern Bolivian Amazon. The Journal of Peasant Studies, London, v. 29, n. 3-4, p. 83-130, apr./jul. 2002.

BAYMA, Marcos. Castanha-do-brasil: cadeia produtiva se destaca no agronegócio acreano. A Gazeta, Rio Branco, p. C1-7, 26 dez. 2012.

BENTANCUR, Marta. Ex-post evaluation of project STDF 114: Sustainable and effective aflatoxin management in Brazil nut. Final report for WTO, jun. 2010.

BRASS, Tom. Towards a comparative political economy of unfree labor: case studies and debates. Library of peasant studies 16. London: Frank Cass, 1999.

Unfree labor as primitive accumulation? CapitalEClass, London, v. 35, n. 1, p. 23-38, feb. 2011.

BRASS, Tom; VAN DER LINDEN, Marcel (Ed.). Free and Unfree Labour: the debate continues. New York: Peter Lang, 1997

CABANES, Guillaume (Org.). Vivências, lutas, memórias: histórias de vida de lideranças comunitárias em Fortaleza. Fortaleza: Fundação D. Rocha, 2002.

CONCEIÇÃO, Manuel. Essa terra é nossa: depoimento sobre a vida e as lutas de camponeses no Maranhão. Petrópolis: Vozes, 1980.

COSLOVSKY, Salo. Economic development without pre-requisites: how Bolivian producers met strict food safety standards and dominated the global Brazil-nut market. World Development, New York, v. 54, p. 32-45, 2014.

COSTA, Rosangela; PIKETTY, Marie; ABRAMOVAY, Ricardo. Pagamentos por serviços ambientais, custos de oportunidade e a transição para usos da terra alternativos: o caso de agricultores familiares do Nordeste Paraense. Sustentabilidade em Debate, Brasília, v. 4, n. 1, p. 99-116, 2103.

CUELLAR, Alvaro (Ed.). Informe de Desarrollo Humano en el Norte Amazonico 2003. La Paz: PNUD, 2003.

CRESPO, Luis. Bolivia: guaraníes 'desamparados'. BBC Mundo, 13 maio 2005. Disponível em: <www.news.bbc. co.uk>. Acesso em: 6 fev. 2014.

FILOCREÃO, Antonio. A castanha no desenvolvimento sustentável da Amazônia. In: SEMINÁRIO INTERNACIONAL - AMAZÔNIA E FRONTEIRAS DO CONHECIMENTO, 9-11 dez. 2008, Belém. Anais... Belém: UFPA, 2008.

FUNDO DAS NAÇÕES UNIDAS PARA A INFÂNCIA - UNICEF. Sin tiempo para soñar: Niños, niñas y adolescentes em la zafra y el beneficiado de la castaña. La Paz: UNICEF, 2008. (Serie Peores Formas de Trabajo Infantil).

GARLAND, Eduardo; SILVA-SANTISTEBAN, Alvaro. Enganche y servidumbre por deudas en Bolivia. Working Paper 41. Genebra: OIT, 2005.

HAGAN, Jim; WELLS, Andrew. Brassed-off: the question of labour unfreedom revisited. International Review of Social History, Cambridge, n. 45, p. 475-485, 2000. 
HELBINGEN, Alan J. B. Balance is beautiful: assessing sustainable development in the rain forest of the Bolivian Amazon. PROMAB Scientific Series 3. Tese (Doutorado em Geografia) - Universidade Utrecht, Holanda, 2001.

KEANE, Jodie; LEMMA, Alberto. The Brazil nut value chain in the northern amazon region of Bolivia. Case study project COPLA. Londres: ODI, 2009.

$\mathrm{KOHN}$, Margaret. Radical space: building the house of the people. Itaca: Cornell University, 2003.

LACERDA, Franciane. Migrantes cearenses no Pará: faces da sobrevivência, 1889-1916. Belém: Editora Açaí, 2010.

LOBO, Cecilia (Coord.). Trabajo infantil y adolescente em Bolivia: guia para la acción. La Paz: Ministério de Trabajo/UNICEF/OIT, 2009.

MACIEL, Raimundo. Certificação ambiental: uma estratégia para a conservação da Amazônia. Tese (Doutorado em Economia) - Universidade Estadual de Campinas, Campinas, 2007.

MACIEL, Raimundo; REYDON, Bastiaan. Produção de castanha-do-brasil certificada na Resex Chico Mendes: impactos e avaliações. Em: CONGRESSO DA SOCIEDADE BRASILEIRA DE ECONOMIA, ADMINISTRAÇÃO ESOCIOLOGIA RURAL - SOBER, XLVI., 20-23 jul. 2008, Rio Branco. Anais... Rio Branco: UNICAMP, 2008.

MARTINS, Elson. Váyase com Dios, Mutran! Página 20, Rio Branco, 10 maio 2004. Disponível em: <www. pagina20.uol.com.br>. Acesso em: 17 out. 2013.

MONTERO, Lourdes; POVEDA, Pablo. Ser castañera: cadena productiva y condiciones laborales de la castaña em Riberalta. La Paz: CEDLA, 2003.

MORI, S. The Brazil nut industry: past, present and future. The New York Botanical Garden, Bronx, NY, 1992 Disponível em: <www.nybg.org/bsci/braznut>. Acesso em: 2 jul. 2013.

NEUMANN, Denise. Indústria quer usar Paraguai contra a China. Valor Econômico, São Paulo, p. C-4, 25 fev. 2014

OEMER, Claudia. Living conditions of forest dependent people in the Northern Bolivian Amazon: a case study of El Sena municipality. Dissertação (Mestrado em Engenharia Florestal) - Universidade Freiburg, Freiburg, 2004.

PACHECO, P; BARRY, D; CRONKLETON, P.; LAR$\mathrm{SON}, \mathrm{A}$. The role of informal institutions in the use of forest resources in Latin America. Bogor, Indonesia: CIFOR, 2008. (Forests and Governance Programmen, n. 15).

PEÑA, Pablo. La castaña y la shiringa en Madre de Dios. Lima: SPDA, 2010. (Cuaderno de investigación, n. 3) .

PUTNAM, Robert. Comunidade e democracia: a experiência da Itália moderna. Rio de Janeiro: FGV, 1995.

RANZI, C. Raízes do Acre. 3. ed. Rio Branco: EDUFAC, 2008.

RIENSTRA, Dianna. Can a nut save the rainforest? International Trade Forum, n. 4, 2004. Disponível em: <www. tradeforum.org>. Acesso em: 10 jul. 2013.
RIBEIRO, Berta (Coord.). Etnobiologia. Petrópolis: Vozes; Brasília: FINEP, 1986. (Suma Etnológica Brasileira, v. 1).

RIBEIRO, M. Ecologia, manejo e sustentabilidade da exploração da castanha-da-amazônia pelos índios Kayapó. 2011. Tese (Doutorado em Biologia Tropical) - Instituto Nacional de Pesquisas da Amazônia, Manaus.

RODRIGUES, G. Caminhando na floresta. Rio Branco: EDUFAC, 2009

ROTHMAN, Franklin. A emergência do movimento dos atingidos pelas barragens da bacia do rio Uruguai 1979-1983. In: NAVARRO, Z. (Org.). Política, protesto e cidadania no campo. Porto Alegre: Editora da UFRGS, 1996.

SAKAMOTO, Leonardo. Os negócios da família Mutran. Carta maior. Trabalho Escravo 3. 19 fev. 2004. Disponível em: <www.cartamaior.com.br>. Acesso em: 10 jul. 2013.

SCOLESE, Eduardo. Pioneiros do MST: caminhos e descaminhos de homens e mulheres que criaram o movimento. Rio de Janeiro: Record, 2008.

SEN, Amartya. Poverty and Famine: An essay on entitlement and deprivation. Oxford: The University Press, 1990.

SERVIÇO DE APOIO ÀS MICRO E PEQUENAS EMPRESAS - SEBRAE. Castanha-do-brasil: opções de investimento no Acre com produtos florestais não-madeireiros. Rio Branco: Sebrae-AC, 1995. (Série Portfólios de Produtos Potenciais da Amazônia).

SILVA, Sheila. Estado e políticas públicas no mercado de castanha-do-brasil no estado do Acre: uma análise pela abordagem do desenvolvimento local. Revista IdeAS, Rio de Janeiro, v. 4, n. 1, p. 103-128, jun./jul. 2010.

SOLT, Frederick. Civics or structure? Revisiting the origins of democratic quality in the Italian regions. British Journal of Political Science, London, v. 34, p. 123-135, 2004.

STOIAN, Dietmar. Shifts in forest product extraction: the post-rubber era in the Bolivian Amazon. International Tree Crops Journal, v. 10, p. 277-297, 2000.

STOIAN, Dietmar. Making the best of two worlds: rural and peri-urban livelihoods options sustained by nontimber forest products from the Bolivian Amazon. World Development, New York, v. 33, n. 9, p. 1473-1490, 2005.

TOLEDO, Karina. Agropecuária brasileira torna-se mais produtiva, porém mais excludente. Comunicado FAPESP, 4 fev. 2014. Disponível em: < http://agencia. fapesp.br/agropecuaria_brasileira_tornase_mais_produtiva_porem_mais_excludente/18569/ > . Acesso em: 6 fev. 2014

TORRES, Rodolfo. Trabajo decente: diagnostico Bolivia. La Paz: CIDA, 2010.

TRIGILIA, Carlo. Small-firm development and political subcultures in Italy. In: GOODMAN, E.; BAMFORD, J.; SAYNOR, P. (Ed.). Small-firms and industrial districts in Italy. London: Routledge, 1989. p. 174-197.

VERITÉ. Research on indicators of forced labor in the supply chains of Brazil-nuts, cattle, corn and peanuts in Bolivia. Verité, Amherst, 2011. 